\section{Secondary Melt Ornamentation On Westwater, Utah \\ Microspherules: Evidence Of An Extraterrestrial Provenance}

J. W. Fandrich - Westwater Group Geological Research Facility

Richard C. Dujay, Ph.D. - Mesa State College Center for Microscopy INTRODUCTION

Microspherules (MS) ranging in size from $50 \mu \mathrm{m}$ to $425 \mu \mathrm{m}$ were discovered at Westwater, Utah in 1999. Examination of these particles using a scanning electron microscope identifies certain physical features that support an extraterrestrial (ET) provenance for these objects. Energy dispersive spectrometry (EDS) was used to determine the qualitative chemistry of these particles.

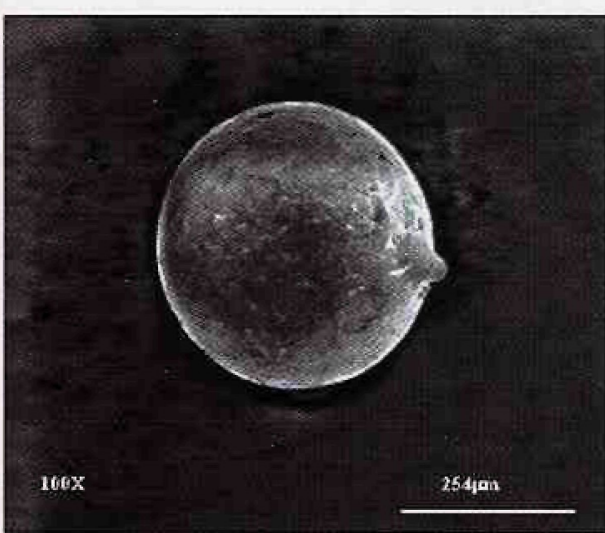

Figure-1 $425 \mu \mathrm{m}$ magnetic crystalline ET MS with an annealed tail.

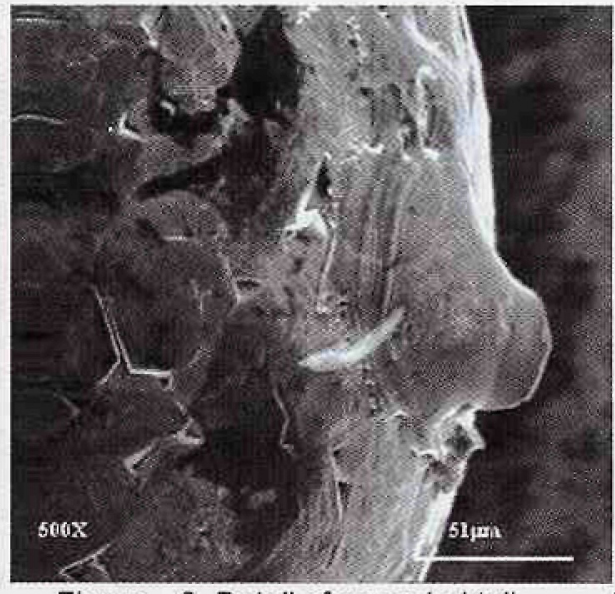

Fiqure - 2 Detail of annealed tail present on a $425 \mu \mathrm{m}$ ET MS ( Fig.-1). altered before slowing to survival speed and a soft landing on the earth surface (Stoke's Law).

\section{SECONDARY MELT CHARACTERISTICS}

Primary MS are formed during their creation events. If these particless have an ET origin and are introduced into our atmosphere there will bo a second time of heating and partial melting (for those MS <600 $\mu m$ and $>200 \mu \mathrm{m}$ ). Secondary alteration melt characteristics include annealed tails, scour grooves, melt migration tracks, leading edge corrosion and ablation rings. When the primary MS is crystalline, the secondary melting can form an amorphous tail (Figs. 1 \& 2). Commonly crystal face melting may bi: present at the crystal to amorphous tail boundary (Fig. 3).

Projectile shaped MS $<600 \mu m(?)$ and $>200 \mu m$ are a relatively commong result of secondary melting (Fig.4). These MS exhibit multiple secondasy melt ornamentation features including ablation rings, melt migration tracks and tails formed from the cooling and redeposition of melt material. Glas MS <600um(?) and $>200 \mu m$ commonly exhibit leading edge corrosion with

\section{MORPHOLOGY}

The majority of MS discovered at Westwater are spherical and cannot be easily identified as different from anthropomorphic spherical MS. Spherical MS are commonly produced by frictional abrasion in roller bearings, brake linings, chop saws, etc. Combustion MS are commonly produced from diesel engines, the burning of coal, cutting torches, effects of welding, and the launch and flight of the space shuttle, etc.

\section{CHEMISTRY}

The elements present in both anthropomorphic and previously discovered ET MS are similar to each other and common throughout the universe. Certain trace elements (i.e. iridium, osmium) can determine an ET origin for certain objects; however, this determination can only be made by complex testing that is beyond the scope of this investigation. The EDS results of the Westwater MS are suggestive of but are not presented as a defining criterion for ET origin. The more common elements present in the Westwater MS are iron and silicon with lesser amounts of fitanium, copper, lead, manganese, potassium, and calcium.

\section{MICROSPHERULE SIZE}

Microspherule size varies greatly from about 1 millimeter to nanomicrometers. Particle size can be important when determining the origin of the particle. Anthropomorphic and ET MS<200um posses similar morphology and chemistry. Extraterrestrial $M S<200 \mu m$ are not affected by entry into the earth's atmosphere. However, ET MS $>200 \mu \mathrm{m}$ and $<600 \mu \mathrm{m}$ (?) are very different from anthropomorphic MS of similar size.

Extraterrestrial MS $>200 \mu \mathrm{m}$ are affected by frictional heating when entering the atmosphere with secondary melt characteristics being superimposed on the surface of these particles. Particles approximately $600 \mu \mathrm{m}$ (?) and greater will completely vaporize when entering our atmosphere at cosmic velocities; however, particles <600um(?) and $>200 \mu \mathrm{m}$ will partially melt and be physically

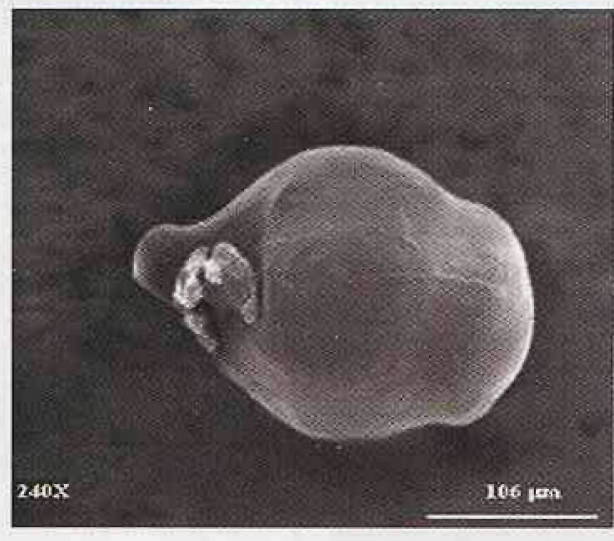

Figure - 4 Projectile shaped ET MS with an ablation ring, melt migration tracks, and a tail resulting from the redeposition of melt material. The flight direction for this MS is from left to right.

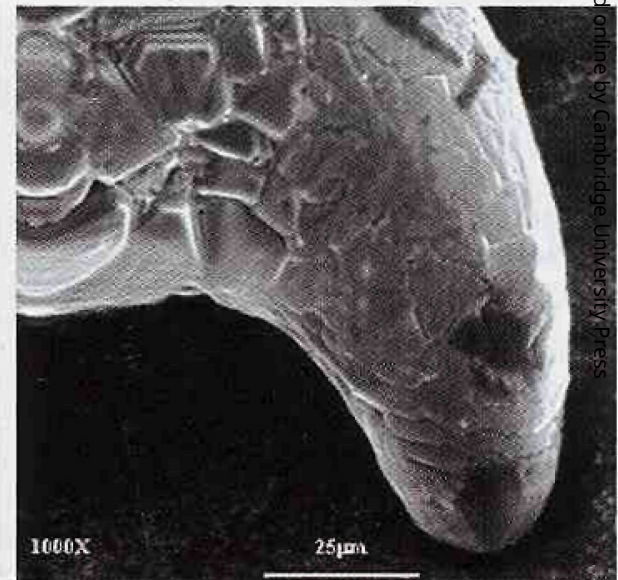

Figure - 3 Detail of the boundary between the crystalline primary ET MS and an amorphous tail. Note the partial to severe melting of the crystals nearest to the amorphous tail.

resulting melt material migration tracks (Fig.5).

\section{CONCLUSIONS}

Extraterrestrial MS $<600 \mu m(?)$ and $>200 \mu m$ when entering the atmosphere at cosmic velocities will experience secondary frictional heating and resulting secondary melt characteristic ornamentation. No earthly process is known to provide for two distinct heating events for these objects. The presence of MS with secondary melt ornamentation at Westwater, Utah identifies these particles as having an ET provenance. 므

1. Varekamp, Johan C. and Thomas, Ellen. 1982, Chalcophile elements in Cretaceous/Tertiary boundary sediments: Terrestrial or extraterrestrial? In Geological Society of America Special Paper 190.

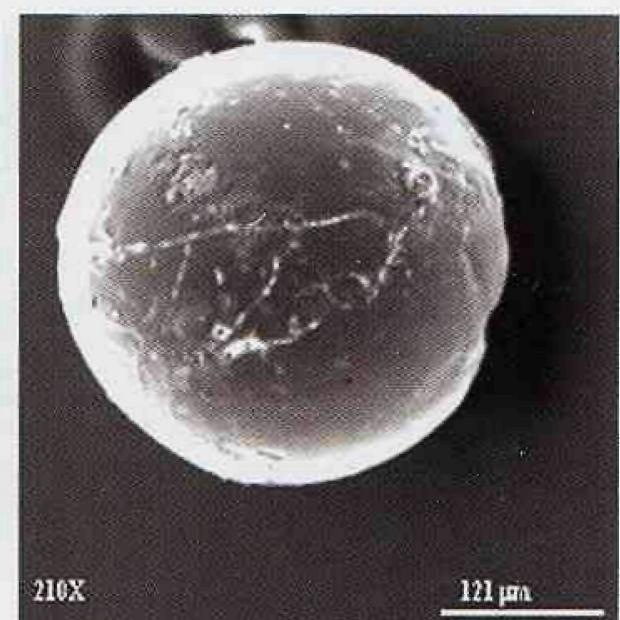

Figure - 5 A glass ET MS with leading edge corrosion (ablation) and melt materia migration tracks. The flight direction for this $M S$ is from left to right. 